\title{
COMPREHENSIVE SURVEY OF WIRELESS COGNITIVE AND 5G NETWORKS
}

\author{
Mr.R.Valanarasu \\ Research Scholar \\ Bharathiar University \\ Coimbatore \\ Email id: valanarasu.r@gmail.com

\section{Dr. Christy A} \\ Professor, \\ Computer Science \\ Sathyabama University \\ Chennai \\ Email id: Christy@gmail.com
}

\begin{abstract}
The tremendous progress in the wireless mobile communication devices and the continuous growth in the data rates and the usage with the entailment of enhanced performance in the network in the terms of the throughput, delay, energy utilization, data capacity, bandwidth utilization and the cost have led to the emergence of the 5G networks. The flexible transmission empowered by the cognitive radio networks make them prominent in the transmission of the applications that are significant and sensitive to latency. The paper surveys the details of the $5 \mathrm{G}$ network, the cognitive radio networks and the impacts in the network by having the cognitive radio in the $5 \mathrm{G}$ mobile wireless networks.
\end{abstract}

Keywords: $5^{\text {th }}$ Generation Network, Cognitive Radio Networks, Data Traffic, Quality of service and Radio spectrum

\section{INTRODUCTION}

The rapid developments in the mobile communication devices and the wireless communication systems causes multitudes of issues that are related to the rates of the data that are very high and the crowded users and the entailment of the users regarding the peer to peer performance and the user acquaintance. In the recent decades the wireless network based on the mobile communication have undergone momentous modifications in the mechanism of the operation such as data capacity, technology, latency frequency and the speed. Many issues come up with the newly arising application that demand for the lower energy consumption, with diminished latency and reduced cost even when equipped with huge set of devices, and data rates pave way for the $5 \mathrm{G}$ wireless networks. The requirement of the wireless network on the terms of delay, throughput, energy consumption and cost has resulted to

ISSN: 2582-337X (online) 
Journal of Ubiquitous Computing and Communication Technologies (UCCT) (2019)

Pages: 23-32

https://www.irojournals.com/jucct/

DOI: https://doi.org/10.36548/jucct.2019.1.003

the development of the $5 \mathrm{G}$ wireless systems. The $5 \mathrm{G}$ being the fifth generation of the wireless communication systems pave way for the simultaneous transmission of the data from both the devices that mobile as well stationary without the necessity of plugging. The emerging $5 \mathrm{G}$ would result with a significant leap in the mobile based wireless technologies. The fifth generation network has the capability of working perfectly in the low frequency networks and the frequencies that are unlicensed. They even provide greater benefits when working with the higher frequencies so they are compatible operating with the millimeter wave and capable of transmitting huge amount of data, the fig 1 below shows the millimeter wireless access

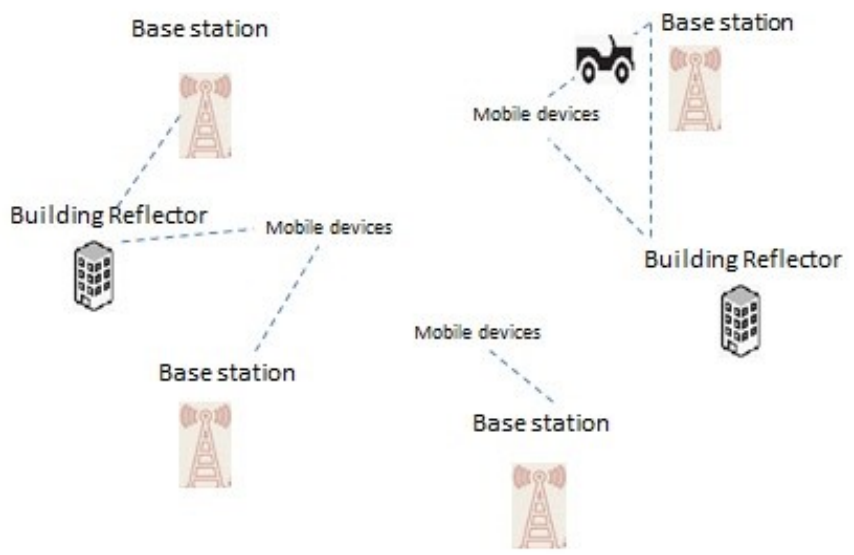

Fig .1 Millimeter Wireless Access

The fifth generation network complements the traditional cellular networks utilizing the smaller cells (portable base stations) and huge number of antennas in the source and the destination to heighten the speed of the transmission and its efficiency. The employing multitudes of antennas lead to the beam forming to frame the trail of the datadelivery effectively and help the multiple antennas to utilize the spectrum in a more efficient way. The $5 \mathrm{G}$ makes use of the full duplex strategy to multiply the speed in the wireless communication. The signal interference caused by the full duplex, necessitates the SDN and the NFV to lay as the foundation for the detailing the deployment of the $5 \mathrm{G}$ networks. The fig. 2 details the essential requirements of the $5 \mathrm{G}$ networks.

ISSN: 2582-337X (online) 
Journal of Ubiquitous Computing and Communication Technologies (UCCT) (2019)

Pages: 23-32

https://www.irojournals.com/jucct/

DOI: https://doi.org/10.36548/jucct.2019.1.003

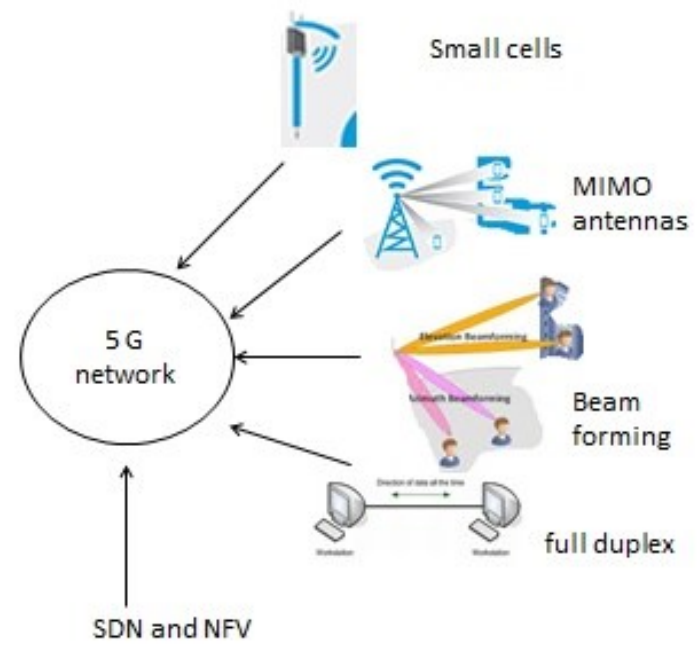

Fig.2 The Essential Requirements of 5G

The cognitive radio network that allows a flexible transmission of the delay sensitive and the significant applications could improve the usage of the congested spectrum in the mobile network by allowing a flexible and a dynamic access of the spectrum and enable the sharing of spectrum with the licensed system. The cognitive radio networks in the $5 \mathrm{G}$ would pave for improvement in the $5 \mathrm{G}$ networks.

The paper is a survey on the significance of the $5 \mathrm{G}$ and the cognitive radio networks and the network enhancements that could be enabled with the cognitive in the $5 \mathrm{G}$.

The remaining of the paper proceeds with the details on evolution of $5 \mathrm{G}$ in the section 2, Significance of the CRN in the section 3 and the impacts in the network caused by the CRN in the $5 \mathrm{G}$ networks in the section 4 and conclusion in the section 5 .

\section{EVOLUTION OF 5G NETWORKS}

The evolution of generation in the wireless networks, usually means the alterations or the modification in the fundamental mannerism of the network such as, their improved capabilities in handling the data rates, the speed in

ISSN: 2582-337X (online) 
Journal of Ubiquitous Computing and Communication Technologies (UCCT) (2019)

Pages: 23-32

https://www.irojournals.com/jucct/

DOI: https://doi.org/10.36548/jucct.2019.1.003

transmission at a reduced cost and the power consumption and even more, usually the high data rates and the increased number of the users lead to the evolving of generations. This all happened to start with the initiation of the first generation network in the 1972, that was purely dependent on the analog to analog networks. The speech services using the analog transmission introduced by the NTT from Tokyo and the advanced mobile phone system introduced by the USA, this mobile telephony service, was supported with the frequency division multiplexing and had a 2 kilobits per second and was very useful in the smaller reuse. In the 1980 the next generation emerged with the digital multiple accesses ensuring a higher bandwidth access and an enhanced efficiency than the first generation later, in the third generation evolved with the even improved clarity by utilizing the wide band wireless network. The fourth generation in the year 2005 emerged with the capability of packet transmission at the real time , the $4 \mathrm{G}$ engaging with the heterogeneous networks faced major problems and complexities due to the increasing data rates and the number of the users, so this lead to the emergence of the fifth generation, that paved way for a limitation less, wireless connections that are complete. The technology would likely expected to offer an higher speed, higher bandwidth, heightened capacity and a larger broadcasting of data with a better coverage and lower latency compared to the previous generations[11][17]. The fig .3 below shows the evolution of generations from the first to the fifth.

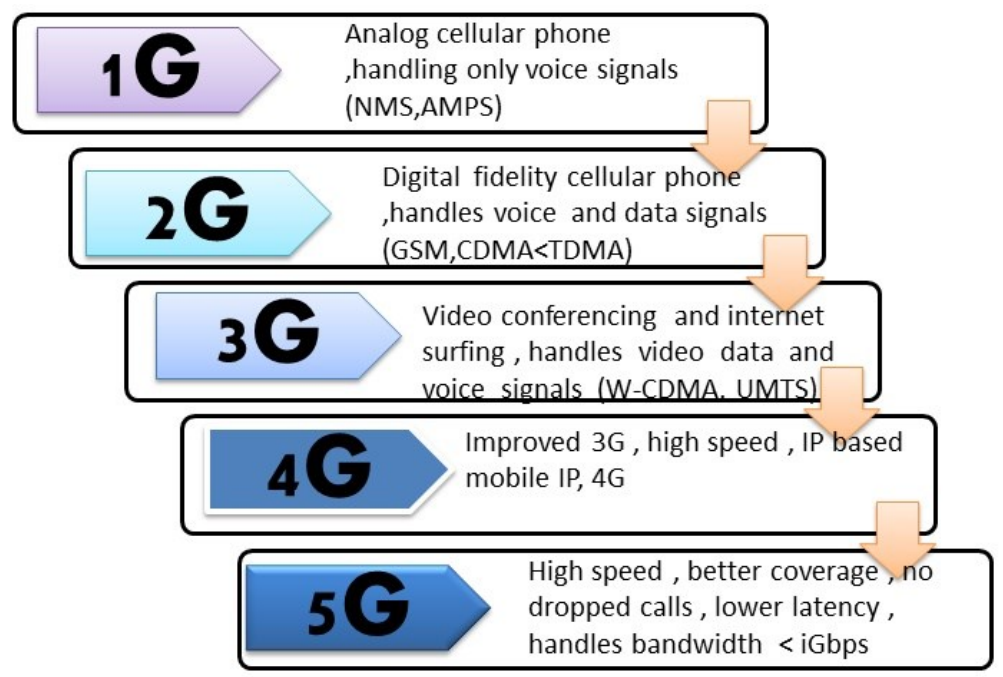

ISSN: 2582-337X (online) 
Journal of Ubiquitous Computing and Communication Technologies (UCCT) (2019)

Pages: 23-32

https://www.irojournals.com/jucct/

DOI: https://doi.org/10.36548/jucct.2019.1.003

Fig.3 Evolution $1 \mathrm{G}$ to $5 \mathrm{G}$

The Fig. 3 gives the evolution of the $1 \mathrm{G}$ to $5 \mathrm{G}$ based on the survey conducted [11] [17]. The complexities of the 4G heterogeneous system, in broadcasting the intimation messages of service confirmation or subscription, challenges in the mobility of the terminals and the inefficiency in the utilization of the spectrum is the cause for the evolution of the next generation that is the $5 \mathrm{G}$, the table below provides the features of the generations from firs to the fifth is presented in the table .1 below [11][17][4][2][9][15]

\begin{tabular}{|c|c|c|c|}
\hline Generations & Descriptions & Merits & Demerits \\
\hline First & $\begin{array}{l}\text { Founded on the year } 1970-1980 \text {, operates at } 2 \mathrm{Kbps} \text {, } \\
\text { with the analog cellular technology based on FDMA, } \\
\text { circuit switching and PSTN as Core network, used in } \\
\text { the analog phone call services }\end{array}$ & $\begin{array}{l}\text { The Mobility in the } \\
\text { provision of service }\end{array}$ & $\begin{array}{l}\text { faced } \\
\text { challenges in } \\
\text { the utilization } \\
\text { of the } \\
\text { spectrum and } \\
\text { the security }\end{array}$ \\
\hline Second & $\begin{array}{l}\text { Founded in the year } 1990-2004 \text {, with a bandwidth of } \\
64 \text { kbps , framed with digital technology } \\
\text { TDMA/CDMA, circuit and packet switching and } \\
\text { used in the digital phones supporting messaging and } \\
\text { the calls with a core network of PSTN }\end{array}$ & $\begin{array}{l}\text { the services provided } \\
\text { were secured and led to a } \\
\text { mass adoption }\end{array}$ & $\begin{array}{l}\text { suffered } \\
\text { from limited } \\
\text { data rates and } \\
\text { found } \\
\text { complications } \\
\text { in handling } \\
\text { the request } \\
\text { for the } \\
\text { internet and } \\
\text { email }\end{array}$ \\
\hline Third & $\begin{array}{l}\text { Founded in the year 2004-10, as an improvement of } \\
2 \mathrm{G} \text { with the bandwidth of } 2 \mathrm{Mbps} \text {, utilizing the } \\
\text { CDMA 2000, UMTS EDGE, operating taking packet } \\
\text { network as the core, and was well suited for phone } \\
\text { calls and the messaging of data. }\end{array}$ & $\begin{array}{l}\text { Provided with a better } \\
\text { experience for the } \\
\text { internet services }\end{array}$ & $\begin{array}{l}\text { showed up } \\
\text { with the } \\
\text { failures in the } \\
\text { internet } \\
\text { access }\end{array}$ \\
\hline Fourth & $\begin{array}{l}\text { Emerged from } 2010 \text { and used till date, is supported } \\
\text { by the core network Internet and is based on the } \\
\text { technology Wi-Max, Wi-Fi, LTE, with CDMA and } \\
\text { was compatible for all IP applications. }\end{array}$ & $\begin{array}{l}\text { Provided a better } \\
\text { performance with the } \\
\text { lower latency in the } \\
\text { internet. }\end{array}$ & $\begin{array}{l}\text { consumes } \\
\text { more energy, } \\
\text { Very costly } \\
\text { (hardware) }\end{array}$ \\
\hline
\end{tabular}

ISSN: 2582-337X (online) 


\begin{tabular}{|l|l|l|l|}
\hline & $\begin{array}{l}\text { Yet to be deployed, provides a higher bandwidth } \\
\text { more than 1Gbp, based on the technology of } \\
\text { WWWW and the core network -internet, functions } \\
\text { using the CDMA, very supportive for the high data } \\
\text { rate applications }\end{array}$ & $\begin{array}{l}\text { Enhanced coverage, no } \\
\text { calls dropping, negligible } \\
\text { latencies and improved } \\
\text { performance. }\end{array}$ & $\begin{array}{l}\text { As the } \\
\text { system is still } \\
\text { in design } \\
\text { process, } \\
\text { would face } \\
\text { certain } \\
\text { challenges in } \\
\text { the } \\
\text { designing. }\end{array}$ \\
\hline
\end{tabular}

Table .1. Features of the Generations from $1 G$ to $5 \mathrm{G}[11][17][4][2][9][15]$

\section{ESSENTIALITIES OF COGNITIVE RADIO NETWORKS $[18,19]$}

The cognitive radio network operating with the assistance of multiple of technologies and also involving the adaptive radio that enables to modify the performance according to the necessities and the intelligent software that replaces the traditional hardware is an intelligent radio network which is adaptive and automated in the detection of the availability of the channels in the wireless spectrum paving way for a simultaneous communication by altering the parameters utilized in the transmission to have a better performance.

It is capable of being configured and programmed according to the availabilities, to have an optimal usage of the channels in the wireless medium and assists in eluding congestion and the user interference. It effectively monitors the radio outputs and its own performance and provides the adjustments in the radio settings based on the changes and offers a better quality of service.

The cognitive radio based on parameters engaged with the transmission and the reception is classified into two main types as fully cognitive observing the changes of all possible parameters and the next one is the spectrum,-sensing cognitive radio that considers only the radio frequency spectrum. They are few other types which depend on the components of the spectrum of the cognitive radio network such as spectrum mobility, spectrum sharing (based on license and sensing and data based), licensed and unlicensed band etc.

The main functioning of the cognitive radio is not limited to spectrum sharing, spectrum sensing, spectrum mobility, spectrum management on the decision in order to ensure an optimal spectrum access [18] where the spectrum sensing is used in determining the spectrum holes and capturing their information. The management on the decision

ISSN: 2582-337X (online) 
Journal of Ubiquitous Computing and Communication Technologies (UCCT) (2019)

Pages: 23-32

https://www.irojournals.com/jucct/

DOI: https://doi.org/10.36548/jucct.2019.1.003

support in selecting the optimal spectrum. Sharing co-ordinates the access of the spectrum with the other users and the mobility ensures channel to be vacated on the reappearance of the licensed users. [19] Based on the survey the table 2 below gives the details of the spectrum sensing sharing and the mobility.

\begin{tabular}{|l|l|l|}
\hline \multicolumn{1}{|c|}{$\begin{array}{c}\text { Functionalities of cognitive } \\
\text { radio networks }\end{array}$} & \multicolumn{1}{|c|}{ Types } & \multicolumn{1}{c|}{ Description } \\
\hline Spectrum Sensing & $\begin{array}{l}\text { 1.Energy detection } \\
\text { 2.Matched filter detection } \\
\text { 3.Feature detection (cyclo- } \\
\text { stationary ) }\end{array}$ & $\begin{array}{l}\text { 1.Easy implementation Does not require } \\
\text { prior knowledge } \\
\text { 2. Acts within shorter time } \\
\text { 3. Easily detects the signal types }\end{array}$ \\
\hline Spectrum sharing & $\begin{array}{l}\text { 1.Licensed and unlicensed } \\
\text { 2. Centralized and distributed } \\
\text { 3. Underlay and overlay } \\
\text { 4.co-operative and non-co- } \\
\text { operative }\end{array}$ & $\begin{array}{l}\text { 1.Free usage and increases spectrum usage } \\
\text { 2.Easy to develop and flexible } \\
\text { 3.Increased spectrum usage and minimum } \\
\text { interference } \\
\text { 4.Increased throughput and suited for small } \\
\text { size network }\end{array}$ \\
\hline Spectrum Mobility & 1. Reactive \\
& 3. Proactive & \multicolumn{1}{c|}{$\begin{array}{l}\text { 4. Compatible for short sensing } \\
\text { Compatible for long sensing } \\
\text { 6. Compatible with general } \\
\text { network (PU) }\end{array}$} \\
\hline
\end{tabular}

Table .2 Functionalities of Cognitive Radio [19]

\section{THE COGNITIVE RADIO INCORPORATED WITH THE 5G}

This section provides the survey on the cognitive radio in the 5G networks. Form the review made it was noted that the cognitive radios can enhance the usage of the congested network. Its capability of integrating the cellular radio that are licensed and cognitive radio into an adverse system has made the cognitive radio network prominent in the fifth generation networks [14] it partially address the issues faced by the fifth generation networks. [2]. they enable the dynamic leasing of the un-utilized spectrums without leading to a harmful interference to its users [15]. They enable to work with the additional spectrum outside the cellular band that is licensed [21] through this dynamic spectrum allocation and their heterogeneous wireless structure they can ensure higher bandwidth utilization to the mobile users [13] they capability of monitoring its own performance and all possible component network to make the radio setting $\mathrm{s}$ adaptive according to the parameter alteration make them even more significant among the fifth

ISSN: 2582-337X (online) 
Journal of Ubiquitous Computing and Communication Technologies (UCCT) (2019)

Pages: 23-32

https://www.irojournals.com/jucct/

DOI: https://doi.org/10.36548/jucct.2019.1.003

generation networks, their efficiency in licensed spectrum as well as the unlicensed spectrum to its primary users through the wideband access become a cost and time saving methodology for the 5G networks. The 5G mobile network that has to become proficient in the handling of the very high data traffic, with higher base station densities, equipment's with the capacity to hold variety of communication devices has the necessity of being designed with the agile spectrum reuse for which the embedding of the cognitive radios in it would be an efficacious approach. Despite the advantages of the cognitive radio in the $5 \mathrm{G}$ networks, it faces few challenges on regard to the antennas, so it is necessary that the cognitive radio network have to ungraded to facilitate the advanced antenna requirements of the fifth generation mobile networks.

\section{CONCLUSION}

The paper providing the comprehensive survey of the fifth generation network and cognitive radio networks and the impacts it created in the network by having a cognitive radio in the fifth generation mobile technology, is presented with the details of the evolution of the $5 \mathrm{G}$ networks, followed by the essentialities of the cognitive radio networks and the impacts created in the network by having the cognitive radio networks in the $5 \mathrm{G}$ network based on the survey proceeded form different literatures, in future they paper is to proceed with the difficulties faced in deploying of the $5 \mathrm{G}$ networks.

\section{REFERENCES}

[1] Bhushan, Naga, Junyi Li, Durga Malladi, Rob Gilmore, Dean Brenner, Aleksandar Damnjanovic, Ravi Teja Sukhavasi, Chirag Patel, and Stefan Geirhofer. "Network densification: the dominant theme for wireless evolution into 5G." IEEE Communications Magazine 52, no. 2 (2014): 82-89.

[2] Monserrat, Jose F., Genevieve Mange, Volker Braun, Hugo Tullberg, Gerd Zimmermann, and Ömer Bulakci.

"METIS research advances towards the 5G mobile and wireless system definition." EURASIP Journal on Wireless Communications and Networking 2015, no. 1 (2015): 53.

ISSN: 2582-337X (online) 
Journal of Ubiquitous Computing and Communication Technologies (UCCT) (2019)

Pages: 23-32

https://www.irojournals.com/jucct/

DOI: https://doi.org/10.36548/jucct.2019.1.003

[3] Chávez-Santiago, Raúl, Michał Szydełko, Adrian Kliks, Fotis Foukalas, Yoram Haddad, Keith E. Nolan, Mark Y. Kelly, Moshe T. Masonta, and Ilangko Balasingham. "5G: The convergence of wireless communications." Wireless Personal Communications 83, no. 3 (2015): 1617-1642.

[4] Agiwal, Mamta, Abhishek Roy, and Navrati Saxena. "Next generation 5G wireless networks: A comprehensive survey." IEEE Communications Surveys \& Tutorials 18, no. 3 (2016): 1617-1655.

[5] Nshimiyimana, Arcade, Deepak Agrawal, and Wasim Arif. "Comprehensive survey of V2V communication for 4G mobile and wireless technology." In 2016 International Conference on Wireless Communications, Signal Processing and Networking (WiSPNET), pp. 1722-1726. IEEE, 2016.

[6] Gohil, Asvin, Hardik Modi, and Shobhit K. Patel. "5G technology of mobile communication: A survey." In 2013 international conference on intelligent systems and signal processing (ISSP), pp. 288-292. IEEE, 2013.

[7] Bukhari, Syed Hashim Raza, Mubashir Husain Rehmani, and Sajid Siraj. "A survey of channel bonding for wireless networks and guidelines of channel bonding for futuristic cognitive radio sensor networks." IEEE Communications Surveys \& Tutorials 18, no. 2 (2015): 924-948.

[8] Jia, Min, Xuemai Gu, Qing Guo, Wei Xiang, and Naitong Zhang. "Broadband hybrid satellite-terrestrial communication systems based on cognitive radio toward 5G." IEEE Wireless Communications 23, no. 6 (2016): 96106.

[9] https://jwcn-eurasipjournals.springeropen.com/articles/10.1186/s13638-015-0302-9

[10] Garg, Vijay Kumar, and Theodore S. Rappaport. Wireless network evolution: $2 G$ to $3 G$. Prentice Hall PTR, 2001.

[11] Sharma, Pankaj. "Evolution of mobile wireless communication networks- $1 \mathrm{G}$ to $5 \mathrm{G}$ as well as future prospective of next generation communication network." International Journal of Computer Science and Mobile Computing 2, no. 8 (2013): 47-53.

[12] Stevenson, Carl R., Gerald Chouinard, Zhongding Lei, Wendong Hu, Stephen J. Shellhammer, and Winston Caldwell. "IEEE 802.22: The first cognitive radio wireless regional area network standard." IEEE communications magazine 47, no. 1 (2009): 130-138.

[13] Akyildiz, Ian F., Won-Yeol Lee, Mehmet C. Vuran, and Shantidev Mohanty. "A survey on spectrum management in cognitive radio networks." (2008).

[14] Hong, Xuemin, Jing Wang, Cheng-Xiang Wang, and Jianghong Shi. "Cognitive radio in 5G: a perspective on energy-spectral efficiency trade-off." IEEE Communications Magazine 52, no. 7 (2014): 46-53.

[15] Ma, Zheng, ZhengQuan Zhang, ZhiGuo Ding, PingZhi Fan, and HengChao Li. "Key techniques for 5G wireless communications: network architecture, physical layer, and MAC layer perspectives." Science China information sciences 58, no. 4 (2015): 1-20.

[16] Badoi, Cornelia-Ionela, Neeli Prasad, Victor Croitoru, and Ramjee Prasad. "5G based on cognitive radio." Wireless Personal Communications 57, no. 3 (2011): 441-464.

ISSN: 2582-337X (online) 
Journal of Ubiquitous Computing and Communication Technologies (UCCT) (2019)

Pages: 23-32

https://www.irojournals.com/jucct/

DOI: https://doi.org/10.36548/jucct.2019.1.003

[17] Vora, Lopa J. "Evolution of mobile generation technology: $1 \mathrm{G}$ to $5 \mathrm{G}$ and review of upcoming wireless technology 5G." Int. J. of Modern Trends in Engineer. and Research 2, no. 10 (2015): 281-290.

[18] Kusaladharma, Sachitha, and Chintha Tellambura. "An overview of cognitive radio networks." Wiley Encyclopedia of Electrical and Electronics Engineering (1999): 1-17.

[19] Alias, Dinu Mary. "Cognitive radio networks: A survey." In 2016 International conference on wireless communications, signal processing and networking (WiSPNET), pp. 1981-1986. IEEE, 2016.

[20] Haykin, Simon. "Cognitive radio: brain-empowered wireless communications." IEEE journal on selected areas in communications 23, no. 2 (2005): 201-220.

[21] Wang, Cheng-Xiang, Xuemin Hong, Hsiao-Hwa Chen, and John Thompson. "On capacity of cognitive radio networks with average interference power constraints." IEEE Transactions on Wireless Communications 8, no. 4 (2009): 1620-1625.

ISSN: 2582-337X (online)

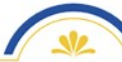

